\title{
THE CONCEPT OF SOCIAL RESPONSIBILITY IN THE BUSINESS MODEL OF A COMPANY
}

\author{
Jevgenijs KUROVS*, Tadeusz WAŚCIŃSKI** \\ Warsaw University of Technology, Faculty of Management, Poland \\ *e-mail: jevgenijs@kbirols.lv \\ **e-mail: t.wascinski@wz.pw.edu.pl
}

\begin{abstract}
The article presents a research topic focused on the issues relating to corporate social responsibility (CSR), which is a component of company's business model. The fact that it is a relatively novel trend in the scope of economics inspired us to raise the aforementioned problem of social responsibility in business, since that area of study is still subject to systematization. The existing interpretation of the concept mainly refers to the questions connected with the commercial sector. CSR is said to be an idea, thanks to which enterprises freely take into account the need for social environmental protection and also relations with various groups of stakeholders at the stage of developing their strategy. Therefore, there is a demand for new scientific studies in that scope. Considering the methodological premises of the article, the author carried out an analysis and evaluation of heating companies in Poland and in Latvia between 2002 and 2014. The analysis was conducted in a dynamic perspective with the use of statistical and econometric tools in order to verify the research hypothesis and achieve the purpose of the thesis. It should be highlighted that a survey questionnaire was the main source of the research data. The study covers 212 out of 445 enterprises operating in the heating sector in Poland and 26 out of 45 operating in Latvia.
\end{abstract}

Keywords: social responsibility, business models, factors: knowledge, macroeconomic, microeconomic, financial, factor analysis, modeling.

1

Introduction

\section{Rationale for the study}

Corporate social responsibility (CSR) is a relatively new area of interest in the field of economics since that area of study is still subject to systematization. The existing interpretation of the concept mainly refers to the questions connected with the commercial sector. CSR is said to be an idea, thanks to which enterprises freely take into account social interest and environmental protection, and also relations with various groups of stakeholders at the stage of developing their strategy.

Not only does being responsible mean meeting all the formal and legal requirements, but also realizing increased investments in human resources, environmental protection, and relations with company's surroundings; in other words, company's engagement on a voluntary basis. Social responsibility is a process within which enterprises manage their relations with various stakeholders who may have an actual influence on the success of their business activity; therefore, such an activity should be treated as an investment, with a given rate of return and broad social benefits.

\section{Main purpose of the article}

The process of deriving a model of CSR supporting heating company management, which, according to the concept standing behind the idea, assumes that also the social interest, relations with the surroundings, and environmental protection are taken into account apart from the economic and financial interest.

\section{Research hypothesis}

A business model taking into account the social responsibility concept in heating company management should consider factors that enable an organisation's sustainable development and create its positive image in the business environment.

\section{Research methods, techniques, and tools}

The presented research problem, the need for verifying the adopted research hypotheses, and the need for developing a business model of managing a heating company in the scope of social responsibility required dividing the research process into specific 
stages. The initial stage of work was predominated by the following methods: direct observation, document test methods, analysis and review of literature. The scientific research techniques used were: survey and interview. Information and knowledge obtained through questionnaires were processed with comparative methods (sample analyses, retrospective analyses, external and internal analyses, and others). The empirical data collected (quantitative and qualitative) were processed with the use of: statistical computation, for example, significance test, correlations between assessments, factor analysis, factor loadings, and so on.

\section{Presentation of research results: business model of managing}

Adopted Business Models in the Scope of CSR for the Purpose of the Article:

Table 1 shows the sequence of the developed business models with consideration of the analyzed factors affecting CSR. Fig. 1 present the main and specific economic factors, which in subsequent parts of the article have been used in the process of modeling the benefits of using the CSR concept.

The process model of social business responsibility macro, micro, and benefits of applying the CSR concept is shown in Table 2.

Table 1. Research areas within CSR business models

(source: drawn on the basis of research results - own study)

\begin{tabular}{|ll|}
\hline \multicolumn{1}{|c|}{ Research areas within CSR business models } \\
\hline I & Process model of social business responsibility (macro) \\
\hline II & Process model of social business responsibility (micro) \\
\hline III & Model advantages of adopting the CSR concept \\
\hline IV & Formal and informal connections within the sector and outside it \\
\hline
\end{tabular}

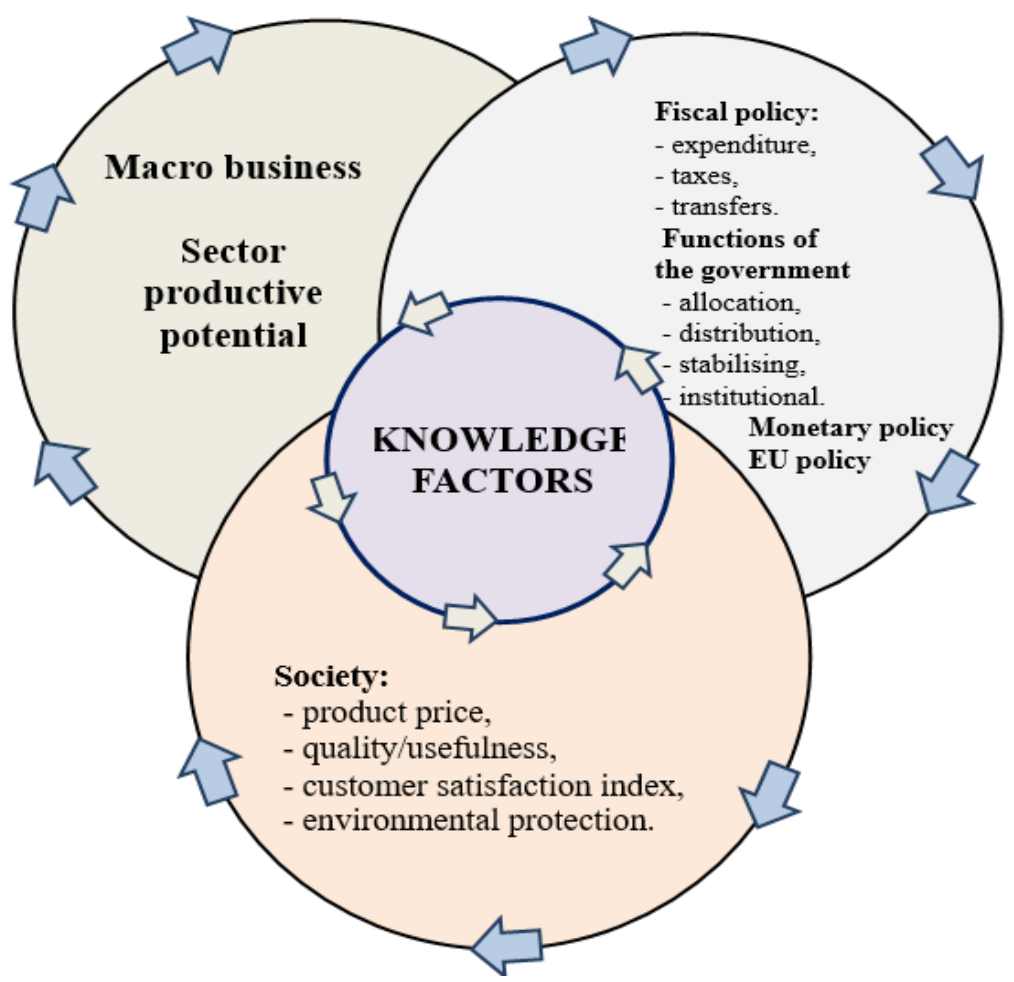

Figure 1. Process model of social business responsibility (macro) (source: drawn on the basis of research results - own study) 
Table 2. Adopted dimensions for prospective factors in models 1, 2, and 3 (source: drawn on the basis of research results - own study)

\begin{tabular}{|c|l|}
\hline Government & $\begin{array}{l}\text { Fiscal policy tools: expenditure, taxes, and transfers. } \\
\text { Functions of the government: allocation, distribution, stabilizing, and institutional. } \\
\text { Monetary policy: interest rates, credit policy. }\end{array}$ \\
\hline $\begin{array}{c}\text { Socio-economic } \\
\text { factors }\end{array}$ & Product price, usefulness, customer satisfaction index, and environmental protection \\
\hline Macro business & $\begin{array}{l}\text { Potential of the heating industry in 2002-2014, } \\
\text { - Dynamics of profits and costs of heating companies in 2011-2013 (Energetyka cieplna } \\
\text { w liczbach, 2013, Energy Regulatory Office, Warsaw 2014) }\end{array}$ \\
\hline Micro business & $\begin{array}{l}\text { Structure of balance sheet, ratio analysis: liquidity, profitability, productivity, and net } \\
\text { profit/division }\end{array}$ \\
\hline Knowledge factors & $\begin{array}{l}\text { Organisational culture, intellectual capital, know-how, learning-by-doing, tacit } \\
\text { knowledge, and crowdsourcing }\end{array}$ \\
\hline
\end{tabular}

\section{Modeling benefits from applying the CSR concept: models for Poland and Latvia}

As a result of the analysis made in order to design the presented models, for the need of this article, a model has been defined as a simplified logical mental construction. In the literature on the subject, one can find that an economic model is, therefore, a collection of assumptions forming a simplified, schematic image of a part or the whole of the economy in which it is possible to study essential relations, disregarding accidental phenomena or phenomena believed to be of minor importance for the purpose of explaining the relevant aspect of economic reality (Klimczak, 1995, p.19).

Having considered this, we adopt the following approach toward the development of business models that take into account the CSR concept.

The modeling of the benefits from adopting the CSR concept has been based on the main factors described earlier. The differences in the approach toward business can be best illustrated with Poland as an example. The data file here is quite extensive, and in the group of companies subject to analysis, there is a sufficient number of enterprises representing a different attitude toward the CSR concept (companies that apply it, do not apply it, or do not know much about it).
The main factors affecting the benefits of the concept (CSR) separated in the conducted analyses allowed to create the model shown in Fig. 2.

Model I for Poland illustrates the influence of the main macroeconomic factors (Macro), socioeconomic factors (SE), microeconomic factors (Micro), knowledge factors (Knowledge), and relationships (PW) on the benefits deriving from applying the CSR concept. In the model, the values quoted in brackets sand for the standard structural parameter errors. In each case, the values of structural parameters are higher than their standard errors, which suggest that individual factors influence the CSR benefits significantly.

In the case of macroeconomic, socio-economic, microeconomic, and knowledge factors, the relation between the value of the structural parameter and its standard error exceeds 2. Therefore, it can be said that the factors have powerful influence on the shaping of the benefits from the CSR concept. Only in the case of this factor, standing behind relationships was an insignificant influence observed (here, the relation between the structural parameter and its standard error fails to exceed 2, although it is close to that). The strongest influence on CSR benefits is given by the micro-economic factor. The impact of the socio-economic factor is also significant. Both, the influence of the macroeconomic factor and knowledge factor is clearly lower, but still they are statistically significant. 


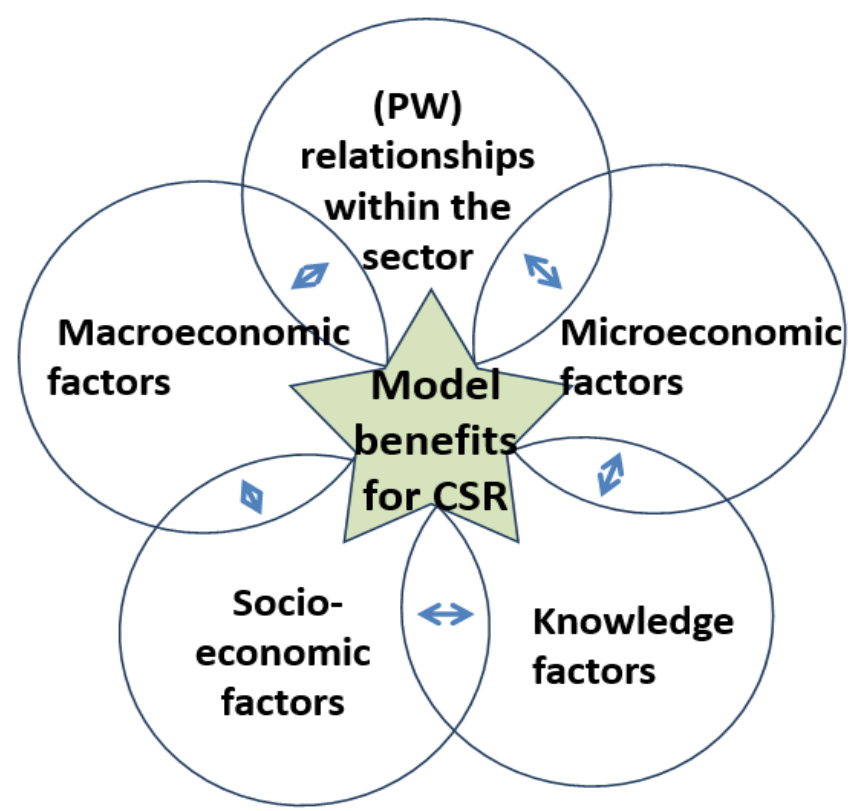

Figure 2. Main factors used in the model of social and business benefits deriving from the application of CSR concept in Models I, II, and III for Poland and Model I for Latvia

(source: drawn on the basis of research results - own study)

\subsection{Poland - Model I}

Benefits_CSR $\mathrm{CSR}_{\mathrm{i}}=-0.000(0.038)+-0.297(0.046) \mathrm{Macro}_{\mathrm{i}}+-0.510(0.071) \mathrm{SE}_{\mathrm{i}}+0.717(0.056) \mathrm{Micro}_{\mathrm{i}}+-0.336$ $(0.046)$ Knowledge $\mathrm{i}_{\mathrm{i}}+0.117(0.069) \mathrm{PW}_{\mathrm{i}}($ the relations in the sector $)+e_{i}$

$$
\begin{gathered}
e_{i^{\sim N\left(0, \sigma_{e}^{2}=0.304(0.029)\right.}} \\
-2{ }^{*} \text { loglikelihood }=304(212 \text { of } 212 \text { cases in use })
\end{gathered}
$$

The next figure depicts a schematic image of the model with information about the factor loadings influencing individual main factors. Fig. 3 presents only those factor loadings that show a correlation with the main factor exceeding $|0.5|$.

Synthesis (theory) of model Poland - Model I is shown in Fig. 3 as following:

regression coefficients have been quoted next to arrows; the red stands for statistical coefficients that are statistically significant. The spare square has been completed with an absolute term. Individual factors have been assigned variables characterized by factor loadings exceeding $/ 0.5 \%$.

The level of error in Model I measured with a variance of random component amounts to 0.304, and in the case of IGLS statistics measuring the goodness of fit of the model - 348.906. In Model I, companies were not differentiated according to whether they apply the CSR model or not. The model was corrected by completing the right side with a zero-one variable representing the approach toward the use of CSR concept. Substituting variable "yes" with value " 1 ," and variable "no" with value " 0 " generates a model for companies employing the CSR concept. Substituting variable "yes" with value " 0 ," and variable "no" with value "1" generates a model for companies that do not employ the CSR concept. Substituting the variable "yes" and variable "no" with value "0" generates a model for companies, which have not expressed their opinion about the use of the CSR concept. In the relevant model, a correction was made according to the constant; companies were not differentiated on the basis of the regression coefficients. 


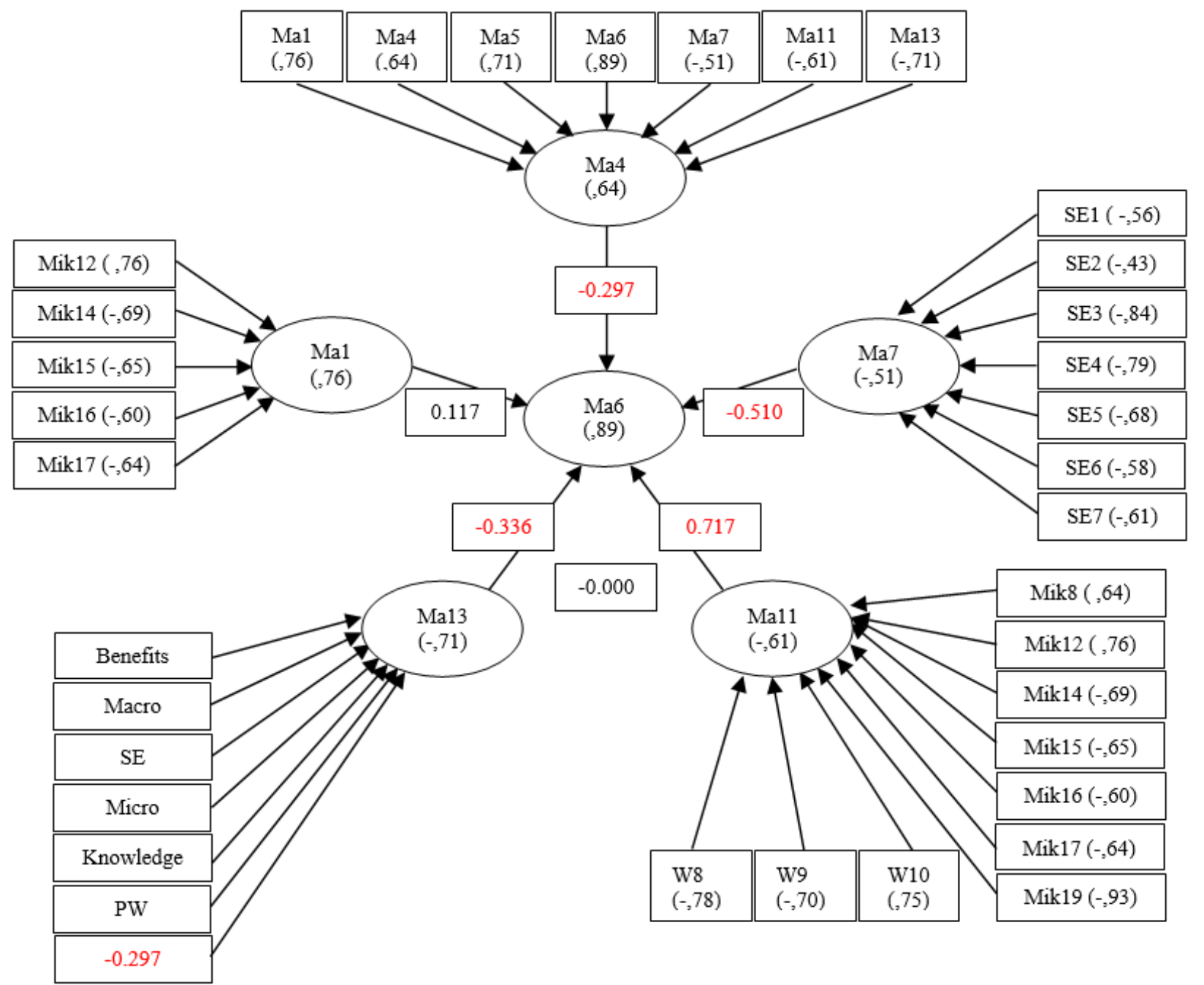

Figure 3. Schematic presentation of Model I for Poland (source: drawn on the basis of research results)

\subsection{Model - Poland II}

Benefits_CSR $\mathrm{C}_{\mathrm{i}}=-1.442(0.108)+-0.395(0.033) \mathrm{Macro}_{\mathrm{i}}+-0.258(0.054) \mathrm{SE}_{\mathrm{i}}+-0.044(0.064) \mathrm{Micro}_{\mathrm{i}}+-0.373$ (0.036)Knowledge $\mathrm{i}_{\mathrm{i}}+0.033(0.049) \mathrm{PW}_{\mathrm{i}}$ (the relations in the sector) $+2.386(0.161) \mathrm{no}_{\mathrm{i}}+1.429(0.121) \mathrm{yes}_{\mathrm{i}}+e_{i}$

$$
e_{i^{\sim N(0,} \sigma_{e}^{2}=0.147(0.014)}
$$

$-2{ }^{*}$ loglikelihood $=195.809(212$ of 212 cases in use $)$

Synthesis (theory) of model Poland - Model II is shown in Fig. 4 as following:

regression coefficients have been quoted next to arrows; the red stands for statistical coefficients that are statistically significant. The empty square has been completed with an absolute term; the first number refers to companies employing the CSR model, the second to companies that do not do that.
Individual factors have been assigned variables characterized by factor loadings exceeding /0.5 /.

The correction made resulted in lowering the variance of the random component to 0.147 , and the value of IGLS statistics to 195.809 , which is statistically significant and substantially improves the model. 


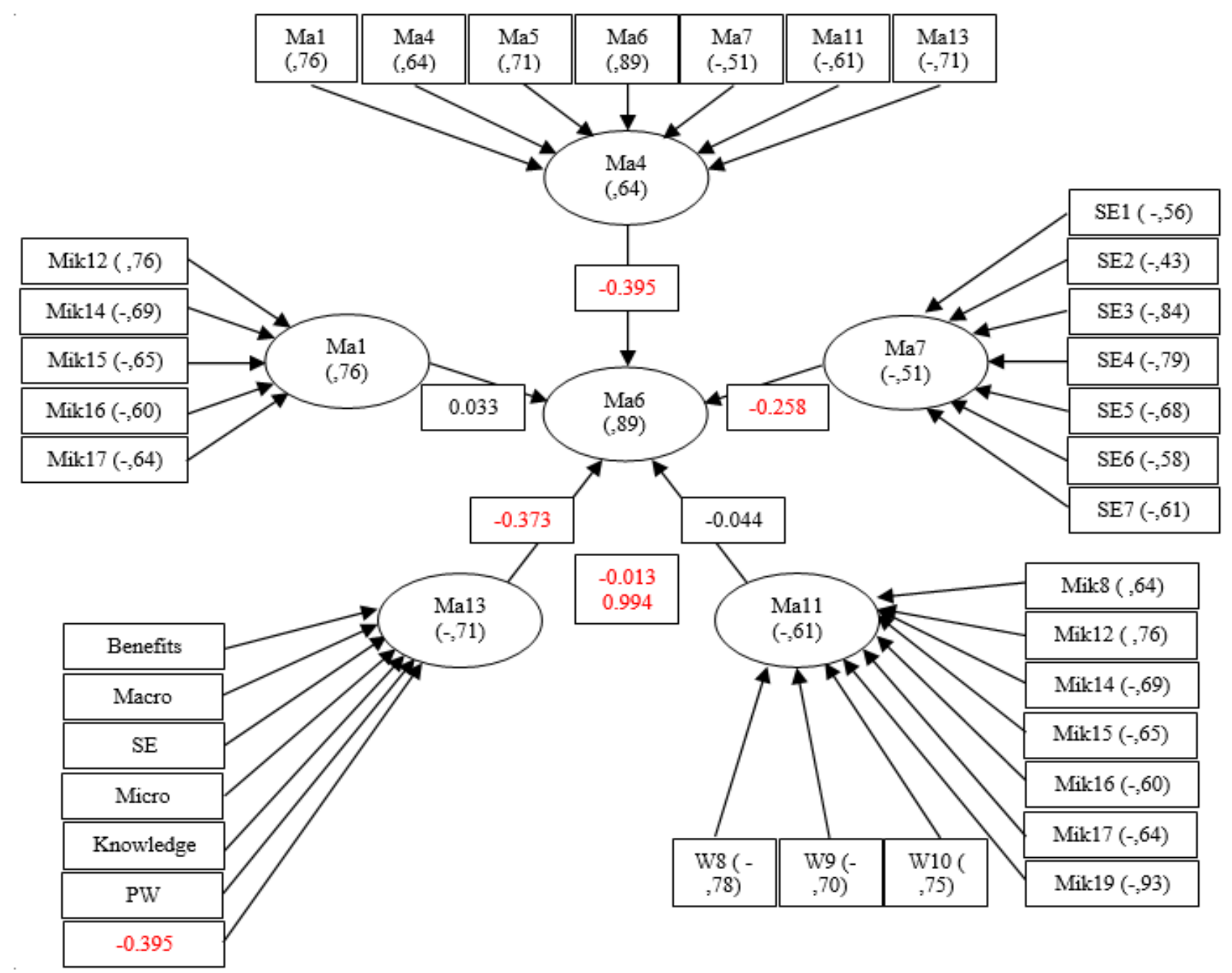

Figure 4. Schematic presentation of Model II for Poland

(source: drawn on the basis of research results)

Worth noting is the fact that the division of the model into companies employing and those not employing the CSR concept resulted in the situation where the micro-economic factor became statistically insignificant. Moreover, the influence of the factor of relationships is also insignificant. It is the practical application of the CSR concept that decides about the informative value of those factors.

The weakness of Model II is the fact the it assumes uniform translation of changes in macro-economic (Macro), socio-economic (SE), microeconomic (Micro), knowledge (Knowledge), and relationship (PW) factors into the benefits from using the CSR concept in companies employing and not employing the CSR model. The model discussed only assumes that the reaction level is different, but the increments are constant. The said fault is not found in the next model, Model III. There, the interactions between macroeconomic (Macro), socio-economic (SE), microeco- nomic (Micro), knowledge (Knowledge), and relationship (PW) factors, as well as the attitudes toward the use of the CSR model are taken into account. The variance of the random component in Model III is at 0.060 , and IGLS statistics, at 6.368. The quoted values prove that it is necessary to consider various levels and various slopes of the CSR benefit model depending on the company's attitude toward the practical application of the CSR concept. In order to obtain a model for a given type of an enterprise, values " 0 " and " 1 " need to substitute the right variable, in the same way as it was done in Model II, for example, in order to generate a regression coefficient of the Macro factor for companies applying the CSR model, it is necessary to replace Macro variable "no" with "0" and Macro variable "yes" with "1." The model is much more complicated than Models I and II, but it explains the analyzed phenomenon much better. 


\subsection{Model - Poland III}

Benefits_CSR $\mathrm{CS}_{\mathrm{i}}=-0.588(0.591)+0.089(0.178) \mathrm{Macro}_{\mathrm{i}}-0.495(0.244) \mathrm{SE}_{\mathrm{i}}+0.319(0.431) \mathrm{Micro}_{\mathrm{i}}+-0.080$ $(0.168)$ Knowledge $_{\mathrm{i}}+0.040(0.222) \mathrm{PW}_{\mathrm{i}}$ (the relations in the sector $)+2.006(0.649) \mathrm{no}_{\mathrm{i}}+0.796(0592) \mathrm{yes}_{\mathrm{i}}+-$ 0.45(0.229) Macro.no ${ }_{i}+-0.732(0.185)$ Macro. yes $_{i}+0.453(0.287)$ SE. no $_{i}+0.127(0.259)$ SE. yes $_{i}+-$ $0.884(0.521)$ Micro. no $_{i}+-0.670(0.435)$ Micro. $y s_{i}+-0.075(0.194) K_{\text {Knowledge no }}+-0.711(0.187)$ Knowledge yes $\mathrm{i}_{\mathrm{i}}+0.016(0.232) \mathrm{PW}$.(the relations in the sector) $\mathrm{no}_{\mathrm{i}}+0.257(0.243) \mathrm{PW}$ (the relations in the sec-

$$
\begin{gathered}
\text { tor }) \cdot \mathrm{yes}_{\mathrm{i}}+e_{i} \\
e_{i^{\sim N\left(0, \sigma_{e}^{2}=0.060(0.006)\right.}} \\
-2{ }^{*} \text { loglikelihood }=6.368(212 \text { of } 212 \text { cases in use })
\end{gathered}
$$

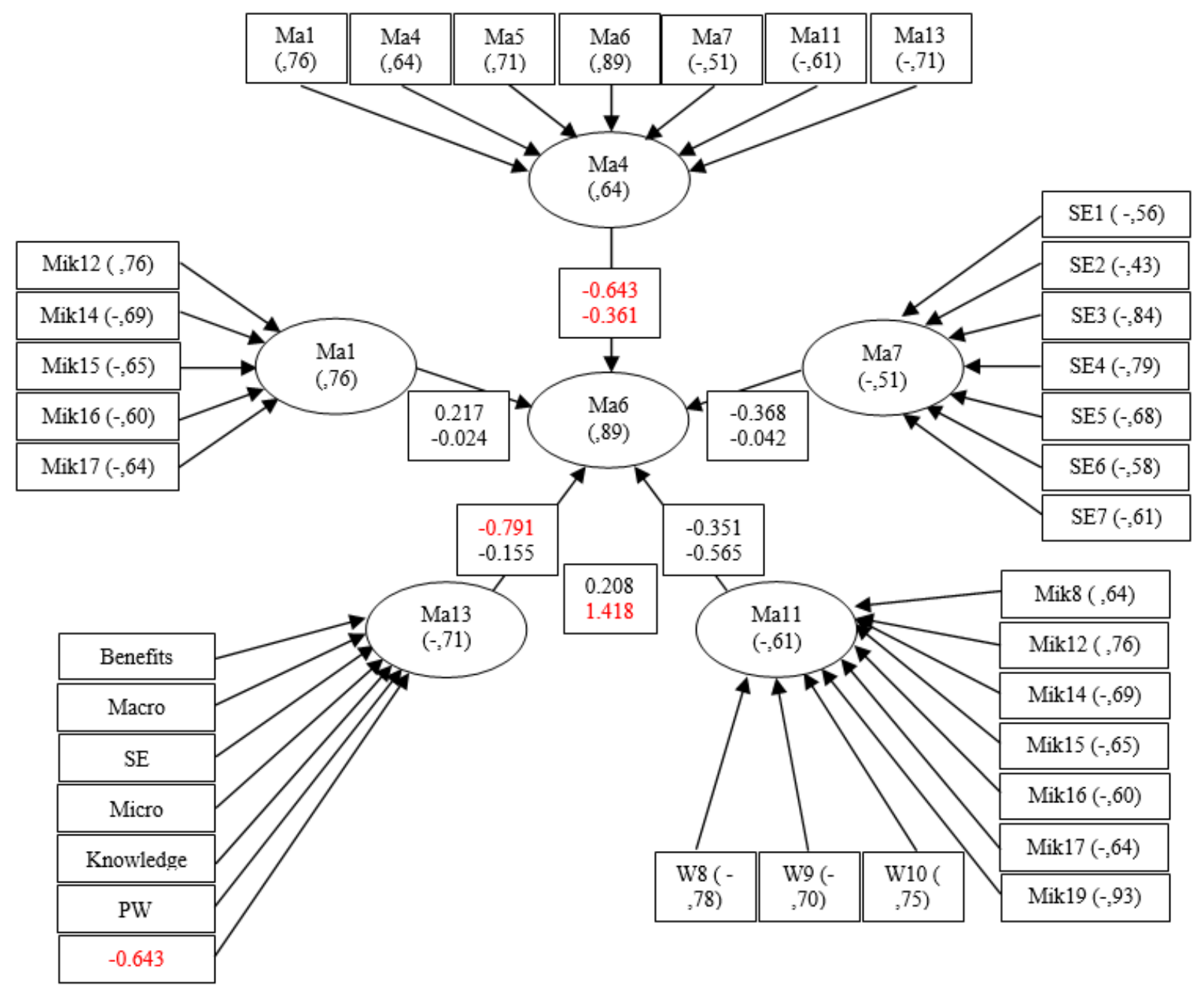

Figure 5. Schematic presentation of Model III for Poland

(source: drawn on the basis of research results)

Synthesis (theory) of the Model - Poland III is shown in Fig. 5 as following:

regression coefficients have been quoted next to arrows; the red stands for statistical coefficients that are statistically significant; the first number refers to companies employing the CSR model, the second to companies that do not do that. The empty square has been completed with an absolute term; the first number refers to companies employing the CSR model, the second to companies that do not do that. Individ- 
ual factors have been assigned variables characterized by factor loadings exceeding / 0.5 /.

Separating the structural regression coefficients according to the company type, the type differentiated on the basis of practical application of the CSR, makes it possible to say that the benefits from the CSR concept in undertakings employing the CSR model are strongly influenced by macro-economic factors and knowledge factors. In companies that refuse to use the CSR model, there are no factors significantly impacting the CSR benefits. Macro- economic, socio-economic, and micro-economic factors are very close to be deemed significant, though. The model clearly shows that the opinion held by companies that do not apply CSR about the CSR is different from its real influence when it is in fact employed.

In the case of Latvia, owing to the one-sided approach presented by companies subject to analysis toward the CSR, only one model was estimated. It is a model for companies employing the CSR concept.

\subsection{Model - Latvia I}

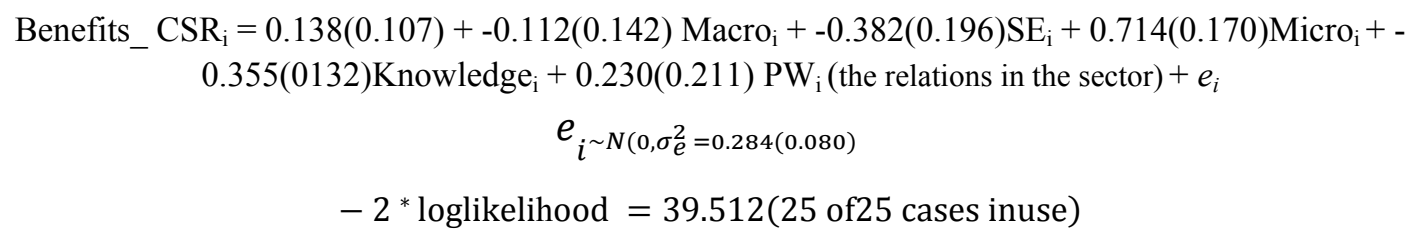

Synthesis (theory) of Model - Latvia I is shown in Fig. 6 as following:

regression coefficients have been quoted next to arrows; the red stands for statistical coefficients that are statistically significant. The spare square has been completed with an absolute term. Individual factors have been assigned variables characterized by factor loadings exceeding / 0.5 /.

The presented model is equivalent to Model - Poland III in the situation when "yes" is replaced with " 1 " and "no" with " 0 " - in other words, in the case of companies using the CSR model in practice.

Due to a smaller sample of companies in the study in Latvia, there is no point in comparing the variance of the random component and the value of IGLS statistics between those models. It is necessary to recognize the model adopted for Latvia as the appropriate one.

When comparing Model - Poland III where yes $=1$ and no $=0$ with the Model - Latvia I, one can notice that the sign of the absolute term, structural parame- ters of the macro-economic, socio-economic, knowledge, and relationship factors is the same in both of them. Only the sign of the micro-economic factor is opposite.

Naturally, other elements shaping individual factors in those countries may be responsible in such a situation, as well. The aforementioned models comprise only the main factors. In Latvia, micro-economic factors and knowledge factors strongly influence the development of benefits from the CSR concept.

The common feature of Polish and Latvian companies employing the CSR model is nothing else by the substantial influence of the knowledge factor on the attaining of benefits from the CSR concept.

It is relatively interesting that the Model - Latvia I is closer to Model - Poland I. The observation mainly refers to the structural parameters. The differences that appear between the two are found in factor loadings. The said discrepancies have been studied in previous parts of the thesis. 


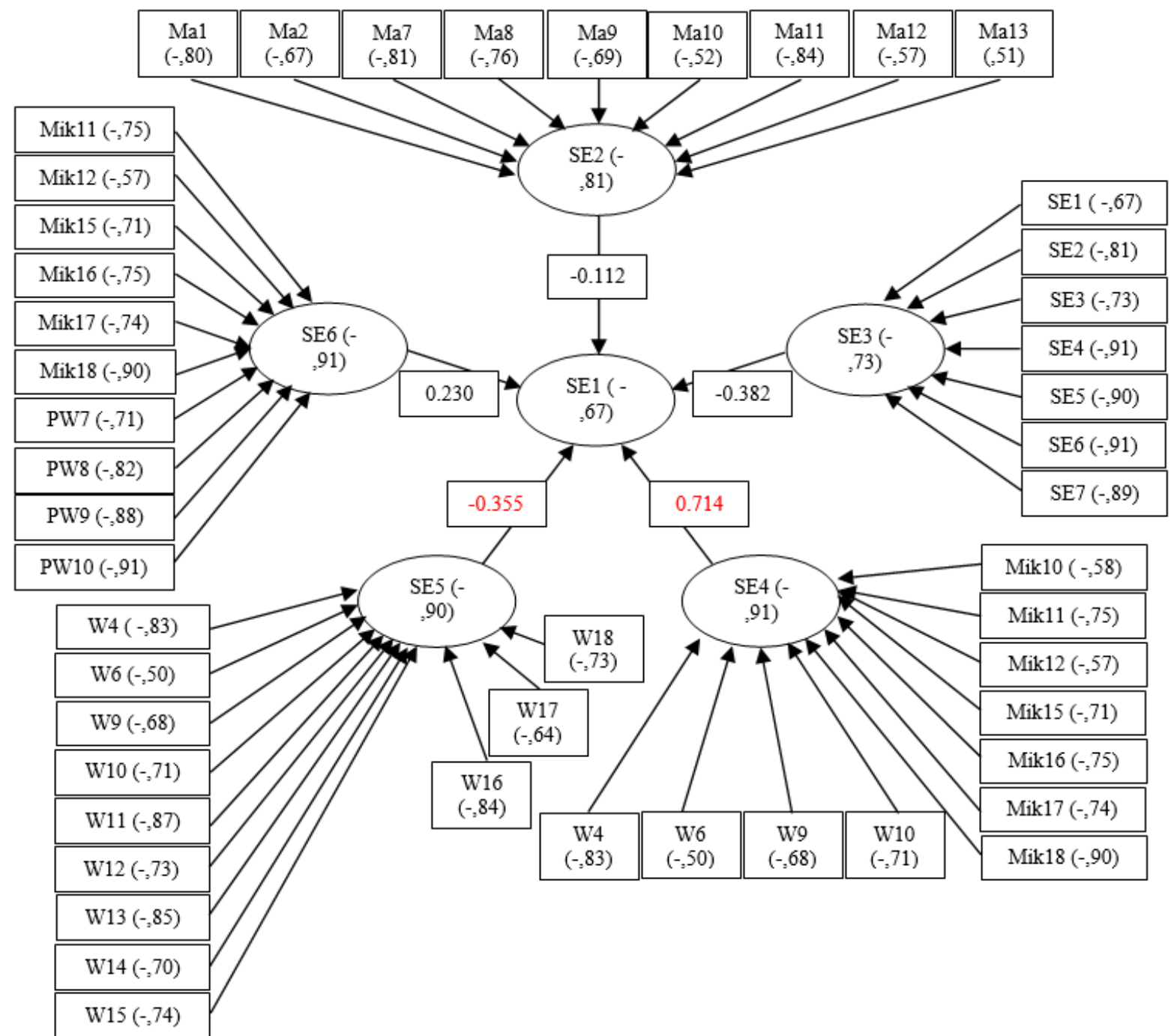

Figure 6. Schematic presentation of Model - Latvia I

(source: drawn on the basis of research results)

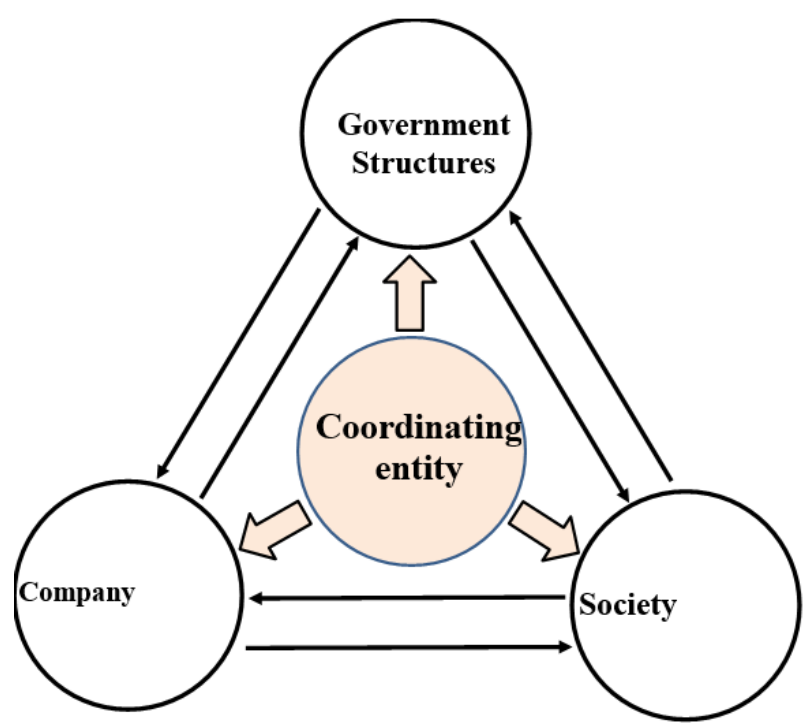

Figure 7. Model A. Business model of managing a heating company in the scope of social responsibility the global viewpoint (research results)

(source: drawn on the basis of research results - own study) 
Models A and B, and I, II, and III in Poland and Model I in Latvia are the result of the earlier conducted analyses, which are shown in Fig. 7.

The business models of heating company management in the context of CSR developed in the article are a proposal of a novel view of the studied issue, namely economic and social success of the heating sector.
In the scope of the theory of management, the prepared models constitute a new instrument supporting decision-making, serving as a factor controlling economic, financial, and social effects. To our mind introducing a coordinating entity responsible for strengthening the implementation of the CSR principles locally will contribute to a more effective introduction of the idea (CSR) and the attaining of mutual benefits.

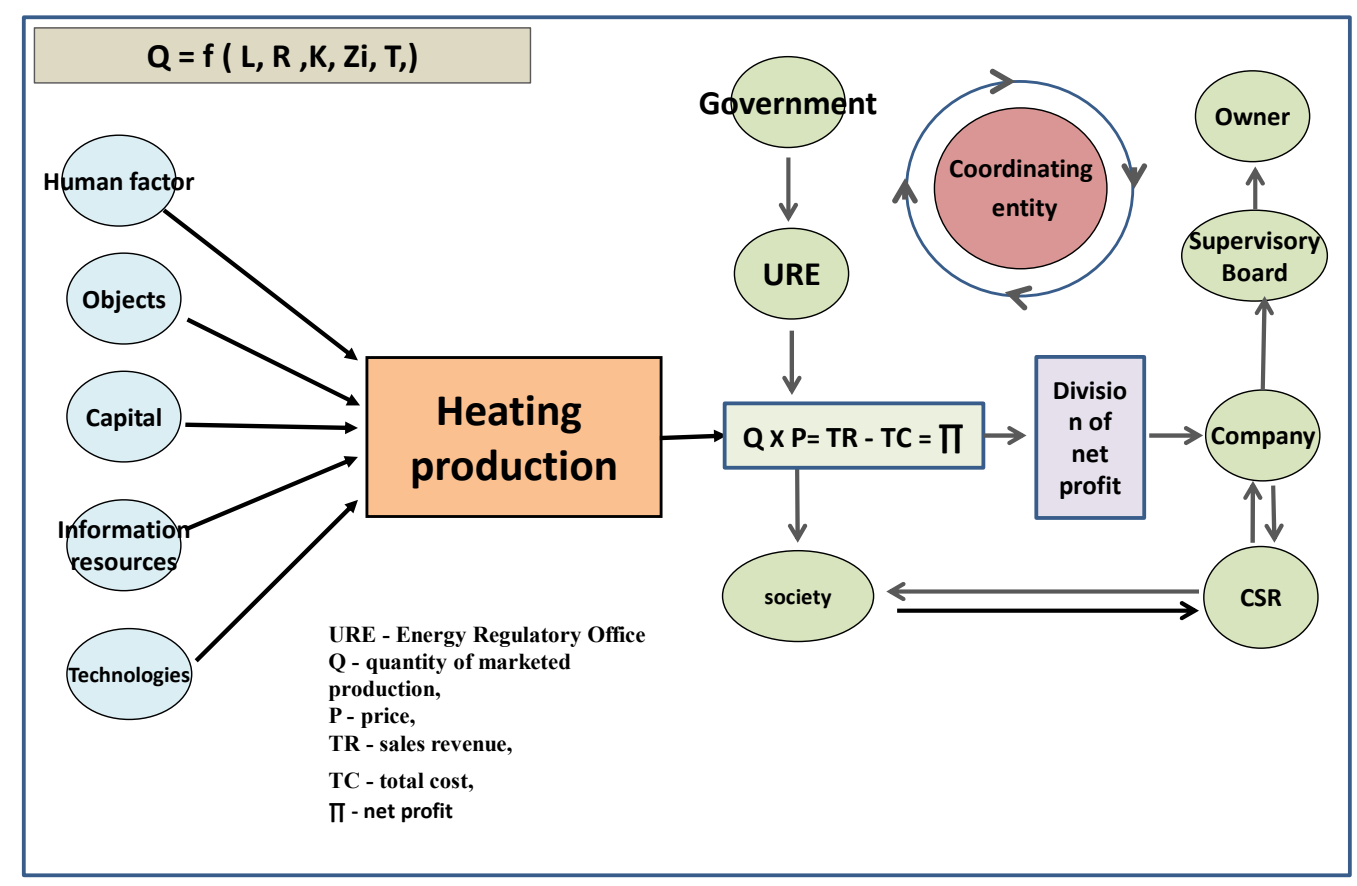

Figure 8 . Model B. Business model of managing a heating company in the scope of social responsibility (on an example of a single company) (source: drawn on the basis of research results - own study)

Model B is shown in Fig. 8, which presents the entrepreneurship in the course of an organized process of actions comprising the employment of necessary production factors focused on the heat energy production.

The business model presented illustrates the cause and reciprocal relations between entities taking part in the process, considering the CSR concept and the role of the coordinating entity, which effectively and efficiently supports the relevant concept (CSR).

We presented the methodology of the research process and the research results.
Moreover, nominal business models in the scope of CSR have been adopted for the purpose of the article: Model I - the process model of social business responsibility - macro, Model II - the process model of social business responsibility - micro, Model III model advantages of adopting the CSR concept. The following factors, previously found in the models, have been singled out: macro-economic factors, micro-economic factors, socio-economic factors, knowledge factors, model benefits from using the CSR concept, and formal and informal relationships within the sector and outside it. Such a structure served the modeling of the benefits from applying the CSR concept in Poland and Latvia. 


\section{$4 \quad$ Summary and recommendations}

Responsible business counts on any strategy that takes into account social, economic, ethical, and ecological aspects in an economic activity and in contacts with partners, employees, clients, contractors, shareholders, suppliers, and local community. It has a good effect on the realization of sustainable economic development policy and such a manner of running a company that perceives attaining balance between effectiveness and profitability of operation and social interest as a priority.

- There is a number of prospective areas of activity that may become places for activating public administration actions in favour of introducing the principles of CSR in Poland and Latvia. What needs to be done is, for instance, setting acceptable standards by companies and public opinion. It ought to be decided what in Polish conditions should determine whether a company can be deemed to be socially responsible: the level of effective energy consumption, the fact of having code of ethics, programs realized in favour of local communities, reliable information on product labels, and so on. The process of defining such standards as well as adequate legal regulations facilitating the implementation of the CSR principles should be supported by the representatives of relevant offices.

- As far as Poland is concerned, these are education and promotion of social responsibility concept that should be treated as the most important areas of operation. Despite the initiatives undertaken by social organisations, such as Responsible Business Forum, the level of knowledge about CSR in Poland is still unsatisfactory. The CSR rules are most spread in large, often international corporations that are the quickest to be reached by world's management trends and are most up-to date in that respect. The situation is reflected in the research on social activity of Polish enterprises, which shows that huge concerns and corporations are the leaders in the field, while only a small part of small and medium enterprises become engaged in social activity.

- The concept of responsible business is not only a new fashion in management, but also a world tendency, which cannot be ignored in Poland and Latvia either. As western companies appeared in the Polish market, access to professional literature was enhanced and training programs became more popular, various components of social responsibility started to spread to management practice. However, the world experience shows that the western standards should not be unquestioningly transferred onto the Polish market without having considered the market level of development, economic, and political culture and advancement in the process of creating a civic society.

- Therefore, a need for running a social campaign on CSR that would be mainly addressed to small and medium heating companies and their stakeholders, in this case among others local communities and social organizations operating at the local level, arises.

The main hypothesis let the authors make the following statement:

The author's models of CSR supporting heating company management assume and confirm that also the social interest, relations with the public, and environmental protection are taken into account apart from the economic and financial interest.

The statistical analysis of data was started by presenting the material collected. The next factors (variables) were described with the use of the following:

- composition of received answers - in tables and distribution graphs,

- descriptive means: average level, standard deviation, median, skewness, kurtosis of distribution.

The statistical significance of the results was checked with the following:

- tests for significance of the difference between the average evaluation of individual variables constituting a given factor,

- correlation (and correlation test) between the responses within pairs of variables constituting a given factor.

The study of the discrepancy between companies in terms of attitude to and use of the CSR model was carried out with the following: 
- test for significance of the difference between the average results observed in answers to successive variables in terms of the attitude toward CSR,

- what was also tested was the interaction between answers given simultaneously in terms of the attitude toward the issue and practical application of the CSR model.

The similarities observed in some questions referring to a given factor indicate redundancy of variables, hence factor analysis was applied in order to reduce the number of variables. The share of each variable in factors (factor loadings) was determined. As a rule, it is possible to reduce a dozen or so factors to a few main ones.

An assessment of the significance of the discrepancy between the specified factors from the viewpoint of the attitude to the issue, the actual use of the CSR model and interactions was also made.

Such a procedure was followed in all groups of variables constituting the set of macro-economic, socioeconomic, micro-economic, and knowledge factors, model benefits of implementing the CSR concept and formal and informal relations inside the sector and outside it.

On one hand, such a study makes it possible to learn about the structure and hierarchy between individual variables and factors, on the other, it lets experts determine the differences between companies from the point of view of their approach towards CSR.

The outcome summarizing the research took the form of models that present the relations between individual macro-economic, socio-economic, microeconomic, and knowledge factors, formal and informal relations inside the sector and outside it and the benefits deriving from applying the CSR concept. In the case of Poland, it turns out that there are two types of companies: the ones that apply CSR and those that do not apply that concept.

On the basis of the data gathered through questionnaires, it is possible to directly make only one model in the case of Poland, that is, the last one.

Taking into account the purpose of the doctoral thesis as well as the verification of the hypothesis and the posed research questions, the author decided to clearly specify the role and importance of CSR in business models. All studies were carried out with the use of MLwiN software (statistical software package for fitting multilevel models).

Therefore, the following assumptions have been made in individual models:

- General Model I that does not introduce any differentiation between companies applying and not applying the CSR concept in their business models in order to determine the influence of individual factors on the socio-economic benefits.

- In Model II, it was assumed that the companies applying and not applying the CSR concept differ in terms of benefits, but the reaction to the changes in macro-economic, micro-economic, socioeconomic, and knowledge factors, and formal and informal relations within the sector and outside it, and so on is the same (the absolute term is different, but the regression coefficients are the same). Such a procedure was adopted in order to define whether the division of companies into the two groups contributes to explaining the phenomenon of the CSR benefits in business models. The IGLS statistics indicate that the answer is yes.

- Model III is the most diversified model of all, since it assumes that not only do companies differ in the level of benefits (a different absolute term), but also in the reaction to macro-economic, micro-economic, socio-economic, and knowledge factors, and formal and informal relations within the sector and outside it, and so on (various regression coefficients). It turns out that such a correction allows us to explain the studied phenomenon better.

- It was necessary to develop three models. If we decided to design only Model III without preparing Models I and II initially, it would not be possible to acquire a full picture whether the perception of CSR benefits in business models is different in these two types of companies. Thanks to observing the changes in the IGLS statistics, we do have such knowledge now.

- Model III in its part referring to the companies applying the CSR concept is an equivalent of the model produced for Latvia. 
As a result, it can be said that companies applying or rejecting CSR differ not only in terms of the average assessment of CSR benefits, but also in the scope of relations between some of the factors with CSR benefits (red colour in the graphs). In the case of Latvia, there is only one model, since all companies subject to analysis in that country applied CSR. It is possible to compare the model for Latvia with the one for Poland, which has been described in the thesis.

The model is simplified as it is based on the first factors from section reduction of variables.

Regression coefficients cannot be subject to a simple interpretation since the factors comprise all variables, and their contribution is determined by factor loadings. However, it is still possible to study the significance of relations and draw a comparison between the countries. The models belong to a broadly defined class of structural models.

The variance of the random component - if we assume that the regression function describes the influence of an independent variable on the dependent variable in a synthetic way, then the remainder illustrates the deviations from the observed pattern. The stronger the deviations are, the stronger influence of accidental factors distorting the observed relation. Residual variation serves as a measure of accidental variations. The root of variation (standard deviation) determines the average empirical deviation of the value of described variable from the theoretical value received from the regression function. Goodness-of-fitting - fitting the theoretical model to empirical data.

\section{$5 \quad$ Bibliography}

[1] Afuah, A., 2004. Business Models: A Strategic Management Approach. New York: McGrawHill Irwin.

[2] Allen, S., 2012. Measuring Energy Security. POSTNOTE. London: Parliamentary Office of Science and Technology.

[3] Amit, R., Zott, C., 2012. Creating Value Through Business Model Innovation. MIT Sloan, Management Review, Magazine: Spring 2012.
[4] Amit, R.H., Zott, C., 2010. Business Model Innovation: Creating Value in Times of Change. IESE Business School - University of Navarra.

[5] Armstrong, G., Adam, S., Denize, S., Kotler, P., 2011. Principles of Marketing (5ed.). Pearson Australia.

[6] Bekmezci, M., 2013. Taking Competitive Advantage by Business Model Innovation. Journal of Management and Economics, Vol. 20, Issue: 1, ISSN-1320-0064.

[7] Bieniok, H., et al., 1997. Metody sprawnego zarzadzania. Warszawa: Placet.

[8] Bonini, S., Gorner, S., 2011. The business of sustainability. McKinsey \& Company (2011).

[9] Briggs, T., 2010. Social Media's Second Act: Toward Sustainable Brand Engagement. Design Management Review, Vol. 21, Issue 1, March 2010.

[10] DECC, 2013. Community Energy in the UK: A Review of the Evidence. Interim Report. Department of Energy \& Climate Change. Undertaken by Databuild Research \& Solutions Ltd, supported by the Energy Saving Trust. [online] Available at:

https://www.gov.uk/government/uploads/system /uploads/attachment_data/file/205218/Communit y_Energy_in_the_UK_review_of_the_evidence. pdf

[11] Drucker, P.F., 1986. Managing for results. New York: HarperCollins Publishers.

[12] Drucker, P.F., 2008. Praktyka zarzqdzania. Warszawa: MT Biznes.

[13] Energy Regulators Regional Association, 2013. Baltic Energy Market Profile. ERRA-Library. [online] Available at:

http://erranet.org/Library/Search?Search=1\&topi c_id $=18$.

[14] GUS, 2011. Wskaźniki Zrównoważonego Rozwo$j u$. Katowice: GUS.

[15] Jabłoński M., Jabłoński A., 2015. Transformacja modelu biznesu w kierunku chmury obliczeniowej. Problemy Jakości, 2015, No 2.

[16] Kaplan, S., 2011. Business Models Aren't Just For Business. Harvard Business Review. [online] Available at: https://hbr.org/2011/04/businessmodels-arent-just-for.

[17] Kaplan, S., 2012. The business model innovation factory. USA: John Wiley \& Sons, Inc. 
[18] Kassi-Vivier, Y., Pawlowski, J., Guttery, C., 2012. Demonstrating the Business Value of Pro Bono Service. Taproot Foundation and Pro Bono Lab.

[19] Leschke, J., 2013. Business Model Mapping: Application And Experience in an Introduction to Entrepreneurship Course. Journal of Entrepreneurship Education, Vol 16, Special Issue.

[20] Parag, Y., Hamilton, J., White, V., Hogan B., 2013. Network Approach for Local and Community Governance of Energy: the Case of Oxfordshire. Energy Policy, No 62, pp.1064-1077.

[21] Skrzypek, A., Senkus, P., 2014. Virtual organization in the new economy. In: A. Skrzypek, ed., Knowledge, innovation and quality as factors of the success in the new economy. Lublin: De- partment of Quality and Knowledge Management Faculty of Economics University of Maria Curie-Skłodowska.

[22] World Economic Forum, 2013. Engaging Tomorrow's Consumer. A report by the World Economic Forum's Sustainable Consumption Initiative. Prepared in collaboration with Accenture, Geneva, January 2013.

[23] Wüstenhagen, R., Boehnke, J., 2012. Business Models for Sustainable Energy. DOI: 10.5339/gse-collection.cop18.16.

[24] Yüksel Mermod, A., Idowu, S.O., eds., 2014. Corporate Social Responsibility in the Global Business World. Springer. [online] Available at: http:/www.springer.com/us/book/97836423761 91. 